\title{
The Effect of Internal Communication, Conflict, Leader Support and Employee Satisfaction on Supply Chain Integration
}

\author{
Muhammad Imtiaz*1 \& Mian Ali Naimat Pervaiz ${ }^{2}$ \\ 1,2 PUTRA Business School, University Putra Malaysia, Malaysia
}

\begin{abstract}
The aim of the study is to find out and improve the strength of supply chain integration thorough testing the effect of antecedents on Supply Chain Integration (SCI). SCI is a key element for improving supply chain performance and competitiveness. The population of the study is manufacturing concerns and data were collected from the managers. The study investigates the hypotheses that internal communication, leader support and employee satisfaction have a positive and significant effect on internal integration but the conflict negatively influences the internal integration. Internal integration subsequently influences external integration. Secondly, the direct impact of internal communication and employee satisfaction on external integration is also tested. The finding shows, all the hypotheses are accepted except one. As well as managerial implications are concerned, managers should equally focus on employee satisfaction and internal communication to have better external integration.
\end{abstract}

Key words: Internal Communication, Conflict, Leader Support, Employee Satisfaction, Supply Chain integration.

\section{Introduction}

The word Supply Chain Management was used as a concept in literature in the mid-1980s however the fundamental assumptions on which SCM is based are older (Cooper et al., 1997). The literature reported that there are two types of Supply Chain Integration (SCI) internal integration and external integration (Narasimhan and Kim, 2002; Swink et al., 2007). Internal integration refers to departments and functions within an organization work as a single cohesive process (Flynn et al., 2010) and External integration refers to formal programs facilitating to the linkage between the trading partners of the supply chain (Jacobs et al., 2016).

This study suggests to managers and firms by finding relationships between antecedents of internal integration to have better external integration and ultimately performance (Jacobs et al., 2016). Practitioners and researchers considered that SCI is important for the success of a firm (Flynn et al., 2010; Prajogo and Olhager, 2012).

Internal integration is also the source of firm performance with its antecedents, leader support, internal communication and conflict (Hieu, 2014). Internal integration significantly has

*Corresponding author.

Email: imtiaz513.pk@gmail.com 
a positive effect on external integration with its antecedents; internal communication and employee satisfaction (Jacobs et al., 2016).

Few researchers first time studied the internal communication in the context SCI (internal and external integration). They filled the research gap by providing empirical evidence that internal communication plays a significant role in enhancing internal and external integration with customers and suppliers (Jacobs et al., 2016). This is the first study evaluating the importance of conflict and leader support on SCI context. This study fills the gap by offering the empirical evidence that leader support significantly enhances the SCI and Conflict negatively affect the SCI. Secondly, empirically proved that employee satisfaction is important than internal communication in the sense of external integration.

The aim of the study is to find the strength of SCI and try to improve integration. The objectives are to find out the antecedent role of Internal communication, Conflict, Leader support and employee satisfaction on internal Integration. Secondly, explore the direct effect of internal communication \& employee satisfaction on external integration. Moreover, it offers a theoretical and contextual contribution. Independent variables are studied through different theories and further this study is conducted in a Pakistani context where supply chain management is growing rapidly.

This study addressed the following questions what are the effects of internal organizational communication, conflict, leader support and employees satisfaction on internal integration and what are the direct effects of internal organizational communication and employee satisfaction on external integration. Previous research offered two variables internal communication and employees satisfaction as factors effecting to internal integration (Jacobs et al., 2016) and offered a research gap to add more antecedents to internal integration. To fulfil the research gap we have added two more antecedents, conflict and leader support. Conflict always exists within the organization when employees communicate vertically in the hierarchy with each other. To resolve the conflict, leader support is required. Thats why the author has been putting leader support after the conflict in the research model of this study. The author has brought these two antecedents through social capital theory, social conflict theory and transformational leadership theory.

Internal communication is the first antecedent of internal integration. The researcher considers communication as a source of integration (Pagell, 2004). The focus of this study is internal integration and it is a vital antecedent to external integration. The construct internal communication has studied with the help of social capital theory. Supply chain management is the source of customer value but if it is integrated well then Internal communication is suitable antecedents to internal integration along with conflict, leader support and employee satisfaction. These antecedents make supply chain well integrated.

The second antecedent in the framework is conflict. Conflict means disagreement. Conflict may exist between two or more persons within society. As it is found in society therefore it has been studied in the context of an organization because ultimately an organization is the part of society. Conflict is a barrier to the strength of supply chain integration (Stevens, 1989). The researcher reported the conflict in two parts i.e. functional conflict and dysfunctional conflict (Hieu, 2014). Functional conflict is used in a positive sense but this study represents the dysfunctional conflict; Dysfunctional conflict refers to disagreement but on the basis of hostility. When employees communicate within an organization the conflict must exist there, then there is the need of leader support for the strength of supply chain integration. Leader support has a direct and positive impact on internal integration that is why this is the third antecedent to integration. The author has studies this construct with the help of two theories i.e. social capital 
theory and transformation leadership theory.

Previous research reported that internal communication is the cause of employee satisfaction (Jacobs et al., 2016). Literature also reported that employees are treated as social agents who communicate widely not only between functions but also with suppliers and customers. When employees communicate widely it directly affects to remove hurdles in understanding the direction (objectives of departments and organization) and ultimately lead to employees satisfaction. A satisfied employee is tending to indulge in serving better than unsatisfied employees (Yee et al., 2008).

As literature was unable to provide support in the mentioned relationships, the impact of antecedent: internal communication, conflict, leader support and employee satisfaction on internal integration in supply chain integration with suppliers and customers but Jacobs et al. (2016) first time provided the platform for future research on supply chain integration with supplier and customers along with two antecedent (Jacobs et al., 2016).

The current studied investigates the direct relationship of internal integration on external integration, Meanwhile, claimed and proved that when internal communication, leader support and employees satisfaction increases between functions (departments) it improves the strength of internal integration which positively impact on external integration with greater strength.

The framework is analyzed through a survey questionnaire. Population for this research is manufacturing concerns. The sample size is 221 and non-probability, convenient judgmental and snowball sampling techniques are used. Before that data collection, experts views are also considered. Data is collected from the manager of the production department, purchase department, Sale and marketing, distribution, inbound logistics and outbound logistics. Crosssectional Study is performed because the author studied the different firms at a single time. The seven-point Likert scale is used in the questionnaire and the scale is totally adopted from the literature (Hieu, 2014; Jacobs et al., 2016). They had performed the reliability test for the scale. Even the questionnaire is adopted but Content validity is performed in this study. Face validity is assured by the experts of linguistics. Finally, data were collected from different manufacturing concerns in Gujranwala, Lahore and Sialkot.

Smart PLS-SEM is used for data analysis all reliability and validity test has performed and found significant results regarding hypothesis t-Test is used which revealed the following results, $\mathrm{H} 1 \mathrm{a}, \mathrm{H} 2, \mathrm{H} 3, \mathrm{H} 4 \mathrm{a}, \mathrm{H} 4 \mathrm{~b}$ and $\mathrm{H} 5$ are accepted because their $\mathrm{t}$ values are more than 1.645 and $\mathrm{H} 1 \mathrm{~b}$ is rejected as its $\mathrm{t}$ value is .97. The results are about similar but also having contradiction point. Previous research gave preference to internal communication on employee satisfaction but this study changes the parameters of thinking. It argued that employee satisfaction has a direct impact on external integration and gives preference to employee satisfaction.

\section{Theoretical Background and Hypotheses Development}

This is the core part of research as it represents all the theories and variables used in this research. Proper justifications are supported for variables.

\subsection{Social Capital Theory}

Social capital theory talks about social capital which further refers to social structure and social assets. Social structure enables the actions of social actors (employees or departmental units). Social assets are generated through interaction among social actors (Inkpen and Tsang, 
2005; Nahapiet and Ghoshal, 1998). Researchers explained the importance of social capital and provided a clear framework (Coleman, 1988; Richardson, 1986). They have performed empirical analysis on it and gave a platform for operationalizing it for further research.

"Social capital is defined by its function; it is not a single entity, but a variety of different entities having characteristics in common: they all consist of some aspect of a social structure, and they facilitate certain actions of individuals who are within the structure" (Coleman, 1990).

Literature provides an extensive view of social capital, which includes future benefits by expanding the relationships between social actors e.g. employees or departments (Jacobs et al., 2016). Social actors derive benefits from social structure and social assets. This study implements the above mentioned extensive view of organizations. Organization systems are a social structure which enables actions between social actors. When social actors interact with each other then social assets come into existence and "internal communication" is one of these social assets (Inkpen and Tsang, 2005). Other social assets conflicts, Leader support and employee satisfaction are also the result of interaction between social actors. Under the social structure of any organization, social assets achieve benefits like "Supply Chain Integration" (Autry and Griffis, 2008).

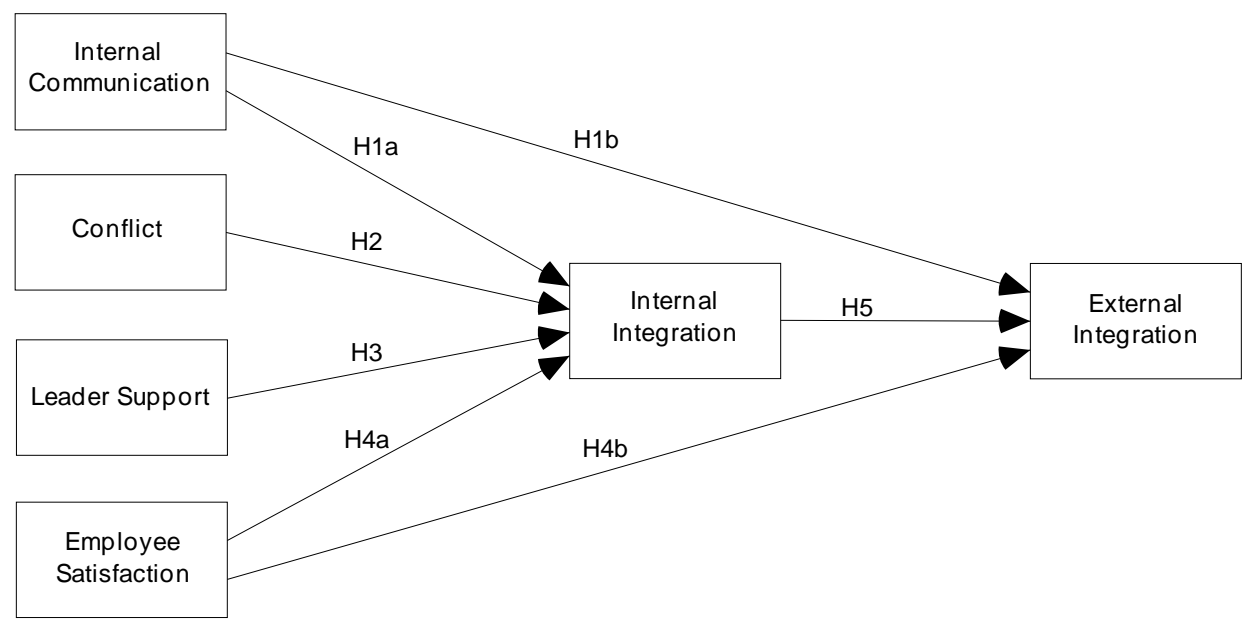

Figure 1: Research Model

From literature and social capital theory, this study has drawn a framework. This model is based on internal and external integration; the research model from the base paper was being consisted only on two independent variables (internal communication and employee satisfaction) and two dependent variables (Internal integration and external integration). They claimed in their study that first time in literature they have offered the effect of internal communication on external integration with suppliers and customers (Jacobs et al., 2016). To fulfil the research gap, the current has added two more antecedents (Conflict and Leader support) to internal integration in the previous model. All these antecedents have not been studied before collectively. This collective model is tested in the Pakistani context. We have added the conflict and leader support as antecedent to internal integration through social capital theory, Social conflict theory and transformational leadership theory. Fig. 1 is showing the model of this study along with 
hypotheses.

\subsection{Effects of Internal Communication}

Communication within the organization exits between departments or employee and it may be formal or informal. Formal communication means, exchanging information between departments or employee under organized meetings whereas informal communication leads to unorganized and unarranged meetings (Le Meunier-FitzHugh and Piercy, 2007). In the current study, the focus is on internal and external integration. Internal communication has a positive and direct effect on external integration (Jacobs et al., 2016).

In todays continuously changing environment, organizational competition has been converted to supply chain based competition (Fernandes et al., 2017). Internal supply chain partners need a strong relationship with external social actors. Under the social capital theory, social actors become the cause of social assets like internal communication which further generates benefits for overall organization, for example, trust, relational norms and information sharing (Tourish and Hargie, 1996). It is proved, in fact, internal communication has a direct effect on internal integration. Therefore in this study, we have also checked the direct impact of internal communication on external integration. In this regard, literature proposes the following hypothesis:

$H_{1}$ a: Internal organizational communication has a significant positive effect on internal integration. $\mathrm{H}_{1} b$ : Internal organizational communication has a significant positive effect on external integration.

\subsection{Conflict and Internal Integration}

In simple words, conflict is the disagreement from important ideas. Conflict exists within the organization and forecasts as producing negative outcomes (Hieu, 2014). Conflict is proved as problematic between supply chain partners (Dong et al., 2016).

This relationship based on this variable is brought with the help of two theories, social capital and social conflict theory. the social capital theory is utilized to talk about conflict generally but it gives the beginning to the conflict in an organization. As mentioned above social capital theory talks about social structure, social assets and social benefits. Social structure is a platform for actors (employees) within an organization and social actors interact with each other and a social asset Conflict comes into existence. Conflict may exist by any disagreement during internal communication. Social conflict theory talks about the behaviour of social groups i.e. (rich, poor). Powerful people in groups always try to get more power and pushing down the lower ones, therefore, they meet with each other on the basis of conflict not on consensus. Almost every organization has a hierarchy level consisting of top management, middle-level management and lower-level management, this division is the same as the social groups offered by social conflict theory. In an organization, conflict may exit vertically or horizontally but vertical conflict tends to more badly than horizontal conflict because the downward pressure of communication in the hierarchy of organization has more power of exploitation of subordinates.

Literature reports the conflict in two parts functional or dysfunctional conflict (Pelled, 1996). Functional conflict leads to improvement in performance whereas dysfunctional conflict became the cause of diminishing it (Prajogo and Olhager, 2012). This study also tests the relationship between dysfunctional conflict and internal integration which further has an impact on external integration. Literature supports the positive hypothesis (Hieu, 2014) but the author has studied the negative impact of conflict through social conflict theory and offers below-mentioned 
hypothesis.

$\mathrm{H}_{2}$ : Internal dysfunctional conflict negatively influences internal integration.

\subsection{Leader Support and Internal Integration}

Literature divulges many leadership behaviours for organizational support (Lee et al., 2010; Srivastava et al., 2006). Leader support has a direct effect on internal integration (Hieu, 2014). Leader job is to provide a medium to a team member for easy sharing of beneficial information.

The construct leader support is derived from the mixture of two theories, Social capital theory and transformational leadership theory. According to social capital theory, when employees interact with each other they start following those ones who inspired them therefore transformational leadership theory explains, $\mathrm{He}$ /she is the leader who inspired the others with great vision and passion. Leader injects the energy in subordinates to perform tasks and then supports them.

The conflict has a negative impact on internal integration therefore leader support plays an important role to fill this gap between employees to improve integration (Le Meunier-FitzHugh and Piercy, 2007). Leader support can change the direction of employees satisfaction level for the betterment of supply chain integration. This study shows the direct impact of leader support on internal integration. We have adopted the hypothesis due to lake of literature support on this variable in the context of internal and external integration (Hieu, 2014).

$\mathrm{H}_{3}$ : Leader support has a significant and positive effect on internal integration.

\subsection{Role of Employee Satisfaction in SCI}

Most of the researchers considered employee job satisfaction as the most important element in their researches (Alegre et al., 2016). Employees are social actors because satisfied employees are more indulged in providing better service quality (Yee et al., 2008). Previous research has studied the direct and indirect impact of employee satisfaction on SCI. After the data analysis, they argued that employee satisfaction has an only direct impact on internal integration not on external integration (Jacobs et al., 2016).

Findings are associated with social capital theory as it talks about the interaction between social actors which leads to benefits (service quality and customer satisfaction) as output. These responses already have tested in various contexts like areas related to organizational liabilities toward supply chain integration. Jacobs et al suggested using these relationships in the way that, coordination between employees increases when employees are satisfied which further amplify the relationships with trading partners (Jacobs et al., 2016).

In order to give the right direction to the relationship of employee satisfaction, the base paper has studied employee satisfaction as an antecedent of internal integration. He has divided impact of employee satisfaction on external integration in two paths, first, he purposed the positive direct impact of employee satisfaction on external integration and secondly the positive impact through internal integration on organizational external integration. As a result of his study, he argued that employee satisfaction has an only direct impact on internal integration. He rejected his hypothesis regarding the direct impact on external integration (Jacobs et al., 2016).

This paper studied the same relationship of employee satisfaction on SCI as mentioned in the base paper. The author used the same relationship because he expected different results in a different context. Again The first impact is as an antecedent to internal integration and second direct impact of employee satisfaction on external integration (Jacobs et al., 2016) is tested in 
Pakistan. Hypotheses are also adopted from above-mentioned base paper because of the same relationship.

In this regard, Literature purposed the following hypotheses:

$\mathrm{H}_{4} a$ : Employee Satisfaction has a significant and positive effect on internal integration.

$\mathrm{H}_{4} b$ : Employee Satisfaction has a significant and positive effect on External integration.

\subsection{Internal Integration and External Integration}

Literature supports a wide range of arguments on supply chain integration (internal and external integration). Integration in the supply chain is a well known concept regarding the distribution of product to the customer since 1970s. Internal collaboration and external collaboration have a positive relationship but Stank et al. (2001) explained it as, "when internal collaboration increases then external collaboration increase". Collaboration between customer and supplies leads to organizational internal collaboration. Literature report this relationship in another different way internal integration leads to external integration. Latest research reports the correlation between information technology, supply chain integration and firm performance. Another viewpoint changes the way of thinking regarding integration which is Internal integration and downstream integration have a positive impact on logistics performance (Germain and Iyer, 2006). Clear visibility of the supply chain is a good source for managers in clear decision making. Companies with a minimum level of internal integration are unable to compete with other firms in the relevant industry. Literature reports the relationship between firms strategic goal and internal integration secondly between external integration and strategic goals (Chaudhuri et al., 2018; Vargas et al., 2000). Internal integration comes into existence and then external integration but social capital has a central role in this relationship (Horn et al., 2014). The further social capital theory provides three dimensions of social capital: cognitive, structural and relational capital, these social capitals dimensions collectively influence the integration. Mark A. Jacobs and Wantao Yu also studied the relationship between internal and external integration with the reference of social capital theory because this is a most prominent theory which clearly talks about social actors and social assets having social benefits for integration (Jacobs et al., 2016).

External integration comprises of Information dissemination, interconnected plans, working with suppliers and customers to solve the problems (Zhao et al., 2011). In literature vast range of researcher choose external integration rather than internal integration (Das et al., 2006; Frohlich and Westbrook, 2001). Wiengarten et al. (2014) explored external integration under the country's logistical capabilities and once again he found a significant relationship.

Latest researchers further explore the supply chain integration with different antecedents. Regarding product complexity, researchers prefer the relationship between internal integration and supplier integration rather than internal integration and customer integration. As development in the services sector, the role of internal and external integration is tested on services innovation. It is found that the customer is integrated as an active resource during the innovation process (Jonas and Roth, 2017). Few researchers investigate the direct and indirect impact of IT capabilities and marketing capabilities on supply chain management.

As mentioned above some researches considered customer integration and some are in favour of supplier integration over internal integration but some of them are focusing on internal integration than external integration. Overall a huge amount of literature supports the solid relationship between internal and external integration however some researchers considered internal integration as an antecedent to external integration (Jacobs et al., 2016). In this 
study, the same relationship utilized, proposed by base studies of Jacobs et al. (2016) and Hieu (2014). He studied supply chain integration but considered the performance as the output of internal integration but in current studies, the pure relationship between internal to external integration is studied by using the combine antecedents to internal integration from Jacobs et al. (2016) and Hieu (2014). This paper has taken; internal integration and employee satisfaction as antecedents to internal integration from the literature of Jacobs et al. (2016) and remaining two antecedents; conflict and leader support have been taken from Hieu (2014) studies. Again hypothesis is adopted from literature because this variable is adopted from research of Jacobs et al. (2016). Thus this study purposes the following hypothesis.

$H_{5}$ : Internal Integration has a significant and positive effect on External integration.

This chapter explained the underlying theories of this study with the theoretical background. Author has explained all variable with literature support and developed the hypothesis for the study. In chapter four this hypothesis will be tested.

\section{Methodology}

The framework in this study is analyzed and tested through a survey using a questionnaire under a positivist stance. The survey questionnaire was used for the purpose of data collection. Results of a new latent variable will enrich the literature with supply chain integration. All variables are tested on the base of empirical evidence to establish the platform for business researchers.

This is an Explanatory study and author studied the new phenomena (framework) to find the results. The population is manufacturing concerns because manufacturing businesses have proper SCM (suppliers and customers) but in the services business, their employees are the supplies. Unit of analysis is top-level and middle-level managers as they have better knowledge about the SCI. Convenient judgmental and snowball sampling technique used to gather the data. The study is analyzed on 221 sample size because literature reports it should be from 100 to 200 (?). The author used 221 sample sizes because the base paper also received 221 respondents. For data analysis, Smart-PLS software is used as we have small sample size and abnormal distribution of data.

\subsection{Population}

As this study is on supply chain integration, the population is educated which can understand the concepts and complexity of the supply chain. The population is manufacturing concerns. To retain the beauty of previous research on supply chain integration, the population is diversified. The population of this study consists of the manufacturer from Plastic furniture, ceramics, sports products, textile, pharmaceutical and packages further all were engaged in sales \& marketing, distribution, Production, Purchases, inbound logistics and outbound logistic for production of tangible products.

\subsection{Sample Size}

For the purpose of data collection, the sample size for this study is 221 . We sent 350 questionnaires and received only 229 filled questionnaire 8 questionnaire were not satisfactory and were removed therefore 221 responses are analyzed. Previous research also received 221 filled 
responses (Jacobs et al., 2016). Literature suggests that the sample size may depend on the number of arrows pointing towards the latent variables and in this study there are 7 arrows pointing towards the latent variable which suggest that the minimum sample size should be 80 strictly but should go for more than 100 or 200 because it is usually a good start for carrying out path modeling (Hoyle, 1995; Wong, 2013).

\subsection{Sampling Technique}

In this study, we have used the sampling techniques on the basis of availability and accuracy of data. Author have used the non-probability sampling techniques and further convenient judgmental and snowball sampling technique. The author collected the data from Gujranwala, Lahore and Sialkot because these are the industrial cities of Pakistan. For the purpose of data, collection author took the expert view in order to gather the data from the right employee and organization. We have selected those business concerns which are having proper training schedules for employees on the basis of different departments. Trained employees are well aware of the organization regarding goals and objectives. After getting the responses from one firm the author had been asked for a close reference from them.

\subsection{Unit of Analysis and Study Type}

The managers of manufacturing concerns are selected as a unit of analysis. Production managers, Purchase managers, Sale managers, Supply chain managers, Outbound and inbound logistics managers, Distribution managers are selected. We have selected these positions because they are directly connected with the movement of product between functions and secondly they are well aware of supply chain integration and have the ability to understand the complexities if SCI (Droge et al., 2004). The author has not studied a few management positions for example; Accounts managers, finance managers and HR managers because they are not directly connected with the product. Literature provides a vast range of study types which can be adopted on the basis of characteristics of the study. This is a cross-sectional study. It refers to the observation of the collection of people at a single time and we have collated the data at a single time.

\subsection{Measures}

The seven-point Likert scale is used in the questionnaire and the questionnaire is adopted from the literature. The email was generating in order to get permission to use the questionnaire.

The base research paper had been using the questionnaire after the amendments and they had also performed the reliability tests.

For measuring the internal communication in the base article (Jacobs et al., 2016). They drew it from Powell and Dent-Micallef, 1997 and used the seven-point Likert scale because they were in favor of communication within the departments. communication leads to employee satisfaction. Employee satisfaction is also tested under a 7 points Likert scale and drawn from Heskett et al. (1994); Kassinis and Soteriou (2003). 1 represents the (strongly disagree) and 7 (strongly agree). For dysfunctional conflict, we have adopted the questionnaire form Hieu (2014). They also express the dysfunctional conflict as it always has a negative impact on internal integration. To reduce the effect of conflict, leader support has been drawn from the literature. The questionnaire for these two items drawn respectively from Le Meunier-FitzHugh and Piercy (2007); 
Mollenkopf et al. (2000). CFA tests were performed by them and found the significant result. Cronbachs alpha coefficient and composite reliability of the constructs is more than the benchmark value 0.07 (Fornell and Larcker, 1981), which refers to the reliability of the questionnaire.

\subsection{Content Validity and Face Validity}

Content Validity is performed in two different phases. First, it is tested through discussion with experts, they offer some changes and the researcher should accept these suggestions. Secondly, it is tested through data analysis software.

In this research, the scale is completely adopted from two research papers. Scales of construct regarding internal communication, Employee satisfaction, internal integration and external integration are adopted from Jacobs et al. (2016) and Scales of Conflict and leader support are taken from Hieu (2014). Both researchers have performed all the validity tests and then developed the scales. The author used these scales to test his research model but after little bit changes of words of an item under the supervision of an expert of the field. The face validity is assured in thesis by the discussion with experts of the field of linguistics. The author met two people for this purpose. They recommended some changes and author accepted their recommendations.

\subsection{Data Collection Procedure}

In order to collect the data we used a convenient judgmental and snowball sampling technique. During data collection from a Strategic Business Units (SBUs) authors ask them to refer us to the next firm. Before the collection of data, it was being made sure that firms are working under proper SC management system.

Data collection was started from BOSS Furniture Gujranwala. On the basis of strong reference data was collected very easily without any delay. As Gujranwala is famous for ceramics therefore 30 questionnaires were collected and Master tiles is foremost of them.

In Sialkot, city data was collected from Awan sports which is one of the big sports firms. Proper permission was taken for this purpose.

In the meanwhile, author sent the question to Bareezya textile unit in Lahore. The questionnaire was sent by email and they took prints and distributed among the managers. The filled questioner was received by author by courier. 36 questionnaires were collected from Plastic and furniture, 33 from textile, 86 from pharmaceutical and medical, 40 from sports, 13 from packages production and 13 from food industries.

\subsubsection{Ethical Considerations}

Researcher refers to some points to be discussed in a research paper (Bryman and Bell, 2007). To ensure the ethical consideration the author has discussed with research participants they will not be subjected to harm in any ways whatsoever. Their respect for dignity will be prioritized. The author has attained the full consent of the respondent before the data collection.

\section{Results and Data Analysis}

This chapter contains an interpretation of the result. It is a most critical part of the study.

For analysis purpose, the smart PLS-SEM techniques and $t$-statistics have been used to measure the validity of measurement models and hypothesis testing. Measurement scales for all 
variables are adopted (Hieu, 2014; Jacobs et al., 2016) and validity and reliability are measured. Hypotheses are tested after validity tests. There is a good range of statistical software but PLSSEM is used because it performs validity tests for reflective models (Haenlein and Kaplan, 2004; Petter et al., 2007).

The second reason to use PLS-SEM is that it does not have any condition regarding the normality of data as it can perform statically tests on both types of distribution of data.

\subsection{Missing Values}

As PLS is also comprehensive software it offers a suitable solution for missing values but conditionally, only if missing values is less than $5 \%$. It fills the missing values by the mean values of the valid values of the same variables (Sarstedt et al., 2017). We have performed the analysis through missing value test and missing values have been replaced with mean values of valid values.

\subsection{Outlier}

It refers to the responses about an item but with abnormal values. The author has used SPSS software to find the outliers. As few unsatisfactory questionnaires have been removed before data entry therefore software has not shown any outlier in data and we further performed the analysis confidently.

\subsection{Descriptive Analysis}

IBM SPSS is used to performed descriptive analysis. We performed descriptive analysis for seven variables which are Respondent age, Respondent Education, gender, year of experience, Industry, department of the respondent, Number of employees in the organization. Regarding age, $63 \%$ of respondents are 20 to 30 year, $29 \%$ of respondents are between 31 to 40 year and $8 \%$ respondent are between 41 to 50 years. Here we have analyzed, respondents with the age range between 20 to 30 years having a greater percentage with the frequency of 139 than all other respondents with age ranges. The second variable is the respondents education. We have divided the education variable in four levels intermediate, Bachelors, Master, and M.Phil. 10\% respondent with the frequency of 21 was intermediate, $45 \%$ of them were bachelors degree holders with the frequency 99, 43\% were masters with frequency 95 and 3\% were M.Phil with the frequency 3. The third variable is respondent gender we used two types of gender i.e. male and female. As we have visited the business organizations personally and observed more strength of male employees than female employees in the Pakistani context. Total valid respondents of this research are 221 and male of them are 204 and female are 17 their percentages are respectively $92 \%$ and $8 \%$.

Regarding year of experience of respondents in the organization are $5 \%$ employees have less than one year of experience, $44 \%$ of total was having 1 to 5 year, 31\% was having 6 to 10 year, $13 \%$ of total valid respondent was having 11 to 15 years and last $7 \%$ of them were 15 year and above. We tried to approach maximum industries but we have focused on the availability and circle of our reach. Here we have $16 \%$ respondents from plastic and furniture, $\% 15$ from Textile, 39\% from Pharmaceutical \& Medical, 18\% from sports, $6 \%$ from packages and $6 \%$ respondents were from the food industry. Data is collected from 6 types of the department because only these departments are closely connected with product development. These are 
Sales and Marketing, Distribution, Purchase, Production, outbound Logistics, Inbound Logistics and their percentages are respectively $23 \%, 18 \%, 34 \%, 24 \%$, and $1 \%$.

Before data collection, we tried to focus those firms having employees strength 400 to 750 . At some extent, we succeeded but under the constraint of limited resources, we collected data also from the firms with below 400 employees.

Further data analysis is performed for the purpose of testing the hypothesis, reliability and validity. Literature supports the below-mentioned steps for further data analysis (Wong, 2013).

1. Outer model loading

2. Indicator reliability

3. Internal consistent reliability / composite reliability

4. Convergent validity AVE

5. Discriminant validity

First we have discussed the validity and reliability tests in detail and then values are interpreted.

\subsection{Outer Model Loadings}

Outer model refers to the relationship between items and latent variable and this outer model loading test represents the correlation between an item and the construct. To find the indicator reliability value, outer loading was seen it must be minimum .4 or above (Hulland, 1999). Default PLS algorithm report is generated first and then we were able to access the outer model loading values for analysis. Internal communication with its 4 items has correlation from .60 to 085 , the four-item of conflict correlation varied from .70 to .86 its mean maximum correlation in items and latent variable conflict is 0.86. Leader support has 3 items Leadsup9, Leadsup10, Leadsup11 and correlation are respectively $.79, .85$, and .82 . The meanwhile correlation varied between Employee Satisfaction and items is .83 to .87. Internal integration with its items; IInt15, IInt16, IInt17, IInt18 and IInt19 have correlation respectively .80, .87, .90, .85 and .83. External integration which is the one of an endogenous variable having 7 items with the maximum correlation .79 and minimum .61, item name ExInt22 have a greater correlation.

All the loading are analyzed and found the significant results even not a single value is less than .4.

\subsection{Indicator Reliability}

This is the second stage reliability test it indicates the individual effect of item on its latent variable. The benchmark value for this test is .4 or above (Hulland, 1999). Reliability test revealed all the indicators showing significant values but four items two from external integration and remaining two from internal communication having the minimum acceptable values which are .4 anyhow reference is cited above. We cannot remove any item having minimum value .4 because if we remove these items, remaining item will not be sufficient for latent variable moreover we are not removing because later reliability tests have shown significant results. 


\subsection{Internal Consistent Reliability/ Composite Reliability}

Most of the researchers have been using the values of Cronbachs alpha to test the internal consistency reliability but literature also reported this technique (Bagozzi and Yi, 1988; Sarstedt et al., 2017). Benchmark for this test is .7 or above but in exploratory study .6 or above is suitable (Bagozzi and Yi, 1988).

The maximum value of composite reliability is .93 for internal integration. It means all five items of internal integration are supporting greater to its latent variable than the support of all the items of other latent variables. On the other hand composite reliability of internal communication by its items is minimum whichis. 83 and it is also acceptable as it fulfils the requirement. The further conflict has .84 composite reliability and leader support having 086. Employee satisfaction is explained by .89 and at last composite reliability of external integration is .85 . Overall all the above values are in the favour of this study.

\subsection{Convergent Validity AVE}

Convergent validity measures at what extent items are related to each other and check whether these items are converged on the same construct. When we perform a composite test on PLS, reports show the AVE test by default. The threshold for convergent validity shows the .5 as a benchmark (Bagozzi and Yi, 1988). Results revealed the truth as external integration having minimum convergent validity .5 it means the items related to this construct are related with each other and convergent on this construct but with the low acceptance level.

\subsection{Discriminant Validity}

In order to perform the discriminant validity, there is a need for correlation of construct between each other. First of all, the report is generated which represents the correlations and then took the square root of AVE values which must be greater than below-mentioned values in the correlation matrix. In this study we observed all the value calculated in the correlation matrix are greater than below values, It confirms the discriminant validity. See table 4.2.

\subsection{Explanation regarding Endogenous Variable Variation}

The coefficient of determinant $\mathrm{R} 2$ refers to how much variation is caused by other latent variables in the endogenous variable. In this study, there are two indigenous variables. The R2 value for internal integration is .664 it means that $66 \%$ variation in internal integration is caused by four other latent variables internal communication, Conflict, Leader support and Employee satisfaction. The R2 value for external integration is 0.360 it means $36 \%$ variation in external integration is caused by three latent variables internal communication, Internal integration and employee satisfaction. The threshold in marketing research represents, R2 of 0.75 is substantial, 0.50 is moderate, and 0.25 is weak (Wong, 2013). According to the above mentioned standard, our model is moderated fit.

\subsubsection{Path Coefficient and Significance}

To test the path coefficient PLS algorithm is required. The model suggested that external integration is strongly affected by employee satisfaction with the value.334, Secondly, internal integration has affected to external integrated by .288 . At number three internal communications 
Table 4.1: Result Summary of Reflective Outer Model

\begin{tabular}{|c|c|c|c|c|c|}
\hline Latent Variables & Items & Loadings & Indicator Reliability & Composite Reliability & AVE \\
\hline \multirow[t]{4}{*}{ Internal Communication } & Com1 & 0.60 & 0.4 & 0.83 & 0.6 \\
\hline & Com2 & 0.65 & 0.4 & & \\
\hline & Com3 & 0.85 & 0.7 & & \\
\hline & Com 4 & 0.84 & 0.7 & & \\
\hline \multirow[t]{4}{*}{ Conflict } & Conf5 & 0.70 & 0.5 & 0.84 & 0.6 \\
\hline & Conf6 & 0.76 & 0.6 & & \\
\hline & Conf7 & 0.86 & 0.7 & & \\
\hline & Conf8 & 0.69 & 0.5 & & \\
\hline \multirow[t]{3}{*}{ Leader Support } & Leadsup9 & 0.79 & 0.6 & 0.86 & 0.7 \\
\hline & Leadsup10 & 0.85 & 0.7 & & \\
\hline & Leadsup11 & 0.82 & 0.7 & & \\
\hline \multirow[t]{3}{*}{ Employee Satisfaction } & EmpSat12 & 0.83 & 0.7 & 0.89 & 0.7 \\
\hline & EmpSat13 & 0.87 & 0.8 & & \\
\hline & EmpSat14 & 0.86 & 0.7 & & \\
\hline \multirow[t]{5}{*}{ Internal Integration } & IInt15 & 0.80 & 0.6 & 0.93 & 0.7 \\
\hline & IInt16 & 0.87 & 0.8 & & \\
\hline & IInt17 & 0.90 & 0.8 & & \\
\hline & IInt18 & 0.85 & 0.7 & & \\
\hline & Int19 & 0.83 & 0.7 & & \\
\hline \multirow[t]{6}{*}{ External Integration } & EXInt20 & 0.70 & 0.5 & 0.85 & 0.5 \\
\hline & ExInt21 & 0.72 & 0.5 & & \\
\hline & ExInt22 & 0.79 & 0.6 & & \\
\hline & ExInt23 & 0.69 & 0.5 & & \\
\hline & ExInt24 & 0.61 & 0.4 & & \\
\hline & ExInt25 & 0.64 & 0.4 & & \\
\hline
\end{tabular}

directly affects to external integration with the vale .082 which is a minimum impact. Above mentioned direct impact of internal integration on external integration is affected by internal communication with the value.295, Conflict with the value .337 , leader support with .223 and employee satisfaction with the vale .117. It has analyzed that conflict has the strongest effect on internal integration and employee satisfaction has the weakest effect on internal integration. 
Table 4.2: Discriminant Validity

\begin{tabular}{lccccc}
\hline Conflict & $\begin{array}{c}\text { Employee } \\
\text { Satisfaction }\end{array}$ & $\begin{array}{c}\text { External } \\
\text { Integration }\end{array}$ & $\begin{array}{c}\text { Internal } \\
\text { Communication }\end{array}$ & $\begin{array}{c}\text { Internal } \\
\text { Integration }\end{array}$ & $\begin{array}{c}\text { Leader } \\
\text { Suport }\end{array}$ \\
\hline Employee Satisfaction & 0.86 & & & & \\
External Integration & 0.52 & 0.7 & & & \\
Internal Communication & 0.41 & 0.42 & 0.74 & & \\
Internal Integration & 0.54 & 0.52 & 0.69 & 0.85 & 0.82 \\
Leader Suport & 0.56 & 0.47 & 0.5 & 0.62 & \\
\hline
\end{tabular}

The hypothesis is tested on the basis of $\mathrm{t}$-Test values $\mathrm{H}_{1} a, \mathrm{H}_{2}, \mathrm{H}_{3}, \mathrm{H}_{4} a, \mathrm{H}_{4} b$ and $\mathrm{H}_{5}$ are accepted because their $t$ values are more than 1.645 and $\mathrm{H} 1 \mathrm{~b}$ is rejected as its $\mathrm{t}$ value is .97 which is less than benchmark 1.645 (Sarstedt et al., 2017). See table 4.3 and framework 4.1 for path coefficient and significance.

With reference to previous research (base paper), we can compare the hypothesis testing. In this study, $\mathrm{H}_{1} a$ is accepted it means internal communication has a direct impact on internal integration. This hypothesis is also supported by the base paper. $\mathrm{H}_{2}, \mathrm{H}_{3}, \mathrm{H}_{4} a$ are also significantly accepted. It refers to conflict negatively influence internal integration. This hypothesis is purely offered by this study and it is strongly accepted. $\mathrm{H}_{3}$ means leader support significantly and positively affect to internal integration. H4a represents the positive effect of employee satisfaction on internal integration. $\mathrm{H}_{4} b$ and $\mathrm{H}_{1} b$ give a great contribution to this study as they rejected the main idea of base research. As $\mathrm{H}_{1} b$ is rejected it means internal communication has no a significant positive impact on external integration and $\mathrm{H}_{4} b$ is accepted it explains that employee satisfaction has a significant and positive impact on external communication. As already mentioned above, the base paper gave a great contribution toward the gap by studying the positive effect of internal communication on external integration. Whereas this study is denying from it by rejecting the hypothesis and gave new direct toward SCI in the Pakistani context. We purposed employee satisfaction is a more important variable than internal integration for SCI.

\section{Discussion}

In this part, the researcher has discussed the study with the reference of results. He has given arguments on the differences and similarities between this study and base paper.

Simply the purpose of this study is to check the strength of supply chain management through supplies chain integration for this purpose we offered two antecedents to internal integration and test the relations with external integration. This type of model is first time introduced in 2016 by Jacobs et al. (2016). He is the first one because he put the two antecedent employee satisfaction and internal communication on internal integration and the subsequent effect on "integration with suppliers and customers". Further, First, we found the gap from previous research (Jacobs et al., 2016) and filled it by introducing two more antecedents to internal integration through theories support and secondly this study is conducted in Pakistan. 
Table 4.3: Hypotheses Testing

\begin{tabular}{lc}
\hline & T Statistics Values \\
\hline Conflict -> Internal Integration & 4.46 \\
Employee Satisfaction -> External Integration & 3.89 \\
Employee Satisfaction - > Internal Integration & 1.92 \\
Internal Communication - > External Integration & 0.95 \\
Internal Communication - > Internal Integration & 4.57 \\
Internal Integration -> External Integration & 3.13 \\
Leader Support -> Internal Integration & 3.65 \\
\hline
\end{tabular}

To test the hypothesis $t$-test has been used but the $t$ values rejected one of hypothesis along with other accepted hypothesis which are, Our hypothesis $\mathrm{H}_{1} a, \mathrm{H}_{2}, \mathrm{H}_{3}, \mathrm{H}_{4} a, \mathrm{H}_{4} b$ and $\mathrm{H}_{5}$ are accepted but $\mathrm{H}_{1} b$ is rejected. We analyzed the internal communication (communication within the functions) have a positive and significant impact on internal integration, the internal dysfunctional conflict has a strong negative effect on internal integration because its t-test value is greater than the values of all other antecedents which is .337. On the other hand, the t-test result surprised us when our hypothesis $\mathrm{H} 1 \mathrm{~b}$ was rejected. It means internal communication has no direct impact on external integration whereas above mentioned previous paper highly supports this relationship. They also claimed that there is not any significant effect of employees satisfaction on external integration but our result denied their views and supports the positive impact of employee satisfaction on external integration. As the interpretation of two contradictive results with previous research we argued that most of manufacturing firms have a touch point between employees, suppliers and customers. Satisfied employees always try to support their organization during these meetings which left the positive impact on externals whereas internal communication is not suitable for external integration because it doesnt have hundred present positive effects on intrinsic factors of employees for their satisfaction.

Two new latent variables as antecedents are brought through more than one theories. Conflict is studied by social capital theory and social conflict theory.

However, there are some similarities between the previous and this research. The positive effects of internal communication and employees satisfaction on internal integration remain the same not with values but on the basis of trends. Internal integration further positively effects on external integration.

From the results, it is proved that the strength of supply chain management can be improved by supply chain integration when the purposed antecedent exists behind the internal integration and external integration.

\section{Conclusion}

This research paper is a tool to ensure the supply chain integration for firms. It provides the valuable variables as antecedents to the model. Framework reveals strategic paths to improve external integration. This integration was tested in china whereas with the added effect of an- 

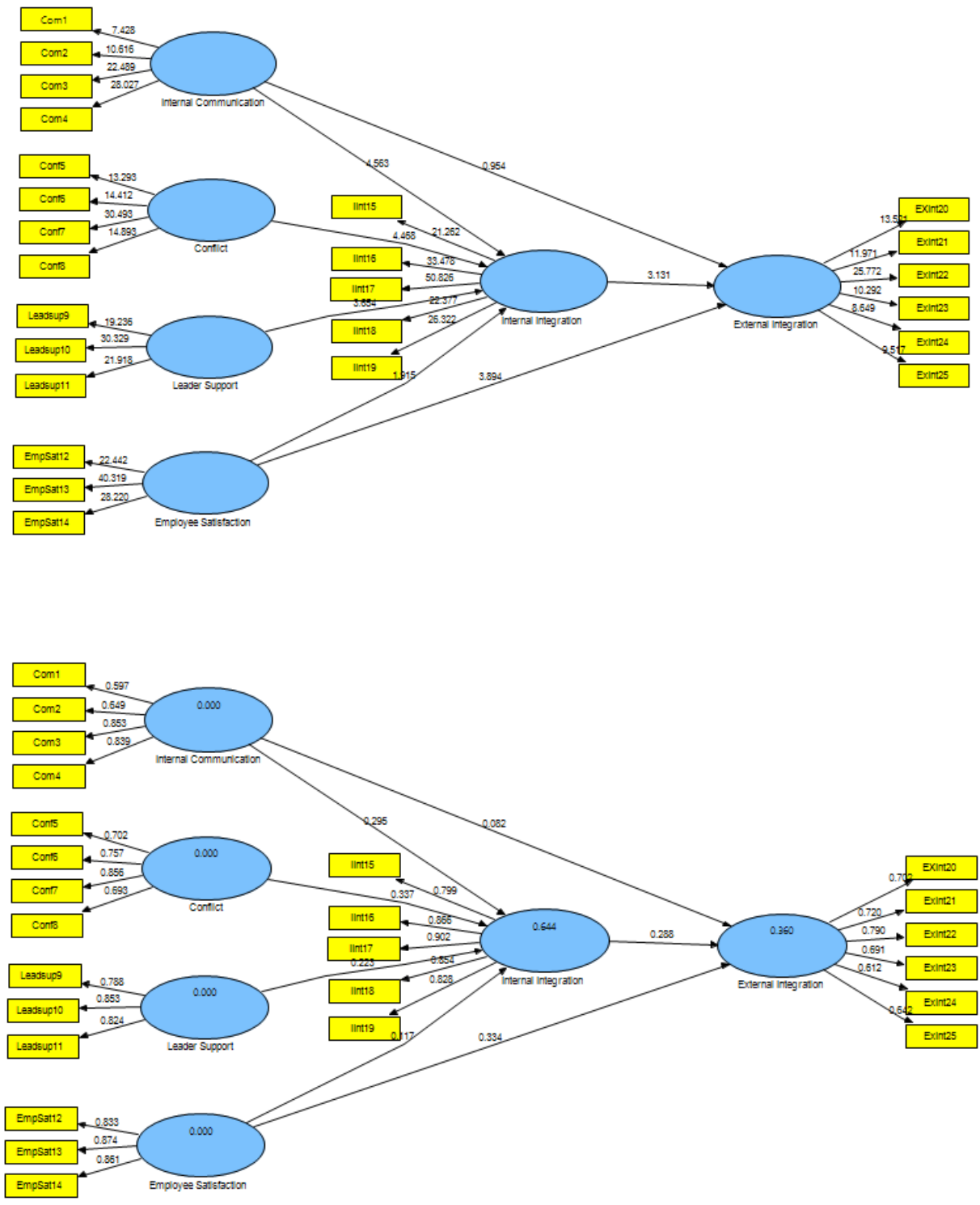

Figure 2: Path coefficient and significance

tecedent this integration has been tested in Pakistan. The purpose was to test this relation in Pakistan because supply chain integration is growing rapidly in Pakistani context.

As Managerial implication, managers should focus equally on internal communication and employee satisfaction for external integration but previous research was fully in the favor of internal communication.

Regarding the ultimate finding of this research, we support above mentioned relationships 
between variables. As this is an explanatory and descriptive study because we have brought two variables in the previously mentioned framework and further explained by using theories and then tested statically.

\subsection{Theoretical and Practical Contribution}

First of all this study has introduced two variables conflict and leader support through suitable theories (Social conflict theory, Social capital theory and Transformational leadership theory). Previous research has offered all variables through a single theory (Social Capital Theory) whereas this study has filled the research gap by theoretical contribution.

Secondly, this study provides new avenues to SCI. It offers that practitioners should focus on leader support to minimize the conflict in an organization. As a result, they will find the strength of internal and external integration because the conflict has a negative impact on integration and leader support is introduced to reduce the negative impact.

As this study has denied the direct impact of internal communication on external integration, especially practitioners should equally focus on employee satisfaction and internal communication for external integration.

\subsection{Limitation and Future Research}

While this study contributes to research and practice, few limitations are required to be considered. Research offers contextual, Methodological and theoretical limitations. As methodological limitation researcher has used survey for data collection but this refers to capturing the conditions of the organization at a time. The researcher can study this model in a long time frame which may reveal the further fact about the antecedent of external integration. The second time this study is tested in Asia. Therefore this is the limitation of the study as we cannot generalize this result on all Asian countries because every county has different economic conditions. Like previous study supply chain integration is tested for manufacturing concerns not for a services business. The future researcher may find the result by applying this model on services. Moreover, the future research may introduce new antecedent to external integration which provides a bridge between internal communication and employee satisfaction for better impact on internal and external integration. Alternatively, the researcher may introduce a moderator between internal communication and external integration and secondly between employee satisfaction and external integration to stable the effect of both antecedents on external integration. Researchers may study the mentioned variable with different theories which refers to the theoretical limitation of this study.

Finally, at the end of this research author discussed the epilogue. After the result, discussions and findings, researcher has understood the depth of supply chain integration. Now he knew there is enough room to add more variables in SCI to study it in different aspects.

\section{References}

Alegre, I., Mas-Machuca, M., and BerbegalMirabent, J. (2016). Antecedents of employee job satisfaction: Do they matter? Journal of Business Research, 69(4):1390-1395.

Autry, C. W. and Griffis, S. E. (2008). Supply chain capital: the impact of structural and relational linkages on firm execution and innovation. Journal of business logistics, 29(1):157-173.

Bagozzi, R. P. and Yi, Y. (1988). On the evaluation of structural equation models. Journal of the academy of marketing science, 16(1):74-94. 
Bryman, A. and Bell, E. (2007). Business research methods second edition oxford university press uk.

Chaudhuri, A., Boer, H., and Taran, Y. (2018). Supply chain integration, risk management and manufacturing flexibility. International Journal of Operations \& Production Management.

Coleman, J. (1990). Foundations of social theory. cambridge, ma: Belknap press of harvard university press.

Coleman, J. S. (1988). Social capital in the creation of human capital. American journal of sociology, 94:S95-S120.

Cooper, M. C., Lambert, D. M., and Pagh, J. D. (1997). Supply chain management: more than a new name for logistics. The international journal of logistics management, 8(1):1-14.

Das, A., Narasimhan, R., and Talluri, S. (2006). Supplier integrationfinding an optimal configuration. Journal of Operations Management, 24(5):563582.

Dong, M. C., Ju, M., and Fang, Y. (2016). Role hazard between supply chain partners in an institutionally fragmented market. Journal of Operations Management, 46:5-18.

Droge, C., Jayaram, J., and Vickery, S. K. (2004). The effects of internal versus external integration practices on time-based performance and overall firm performance. Journal of operations management, 22(6):557-573.

Fernandes, A. C., Sampaio, P., Sameiro, M., and Truong, H. Q. (2017). Supply chain management and quality management integration. International Journal of quality $\mathcal{E}$ reliability management.

Flynn, B. B., Huo, B., and Zhao, X. (2010). The impact of supply chain integration on performance: A contingency and configuration approach. Journal of operations management, 28(1):58-71.

Fornell, C. and Larcker, D. F. (1981). Structural equation models with unobservable variables and measurement error: Algebra and statistics.
Frohlich, M. T. and Westbrook, R. (2001). Arcs of integration: an international study of supply chain strategies. Journal of operations management, 19(2):185-200.

Germain, R. and Iyer, K. N. (2006). The interaction of internal and downstream integration and its association with performance. Journal of business logistics, 27(2):29-52.

Haenlein, M. and Kaplan, A. M. (2004). A beginner's guide to partial least squares analysis. Understanding statistics, 3(4):283-297.

Heskett, J. L., Jones, T. O., Loveman, G. W., Sasser, W. E., Schlesinger, L. A., et al. (1994). Putting the service-profit chain to work. Harvard business review, 72(2):164-174.

Hieu, N. T. (2014). An investigation of the relationships between internal integration, antecedents and functional performance in vietnam. Journal of Economics and Development, 16(2):78-92.

Horn, P., Scheffler, P., and Schiele, H. (2014). Internal integration as a pre-condition for external integration in global sourcing: a social capital perspective. International Journal of Production Economics, 153:54-65.

Hoyle, R. H. (1995). Structural equation modeling: Concepts, issues, and applications. Sage.

Hulland, J. (1999). Use of partial least squares (pls) in strategic management research: A review of four recent studies. Strategic management journal, 20(2):195-204.

Inkpen, A. C. and Tsang, E. W. (2005). Social capital, networks, and knowledge transfer. Academy of management review, 30(1):146-165.

Jacobs, M. A., Yu, W., and Chavez, R. (2016). The effect of internal communication and employee satisfaction on supply chain integration. International Journal of Production Economics, 171:60-70.

Jonas, J. M. and Roth, A. (2017). Stakeholder integration in service innovation-an exploratory case study in the healthcare industry. International Journal of Technology Management, 73(13):91-113. 
Kassinis, G. I. and Soteriou, A. C. (2003). Greening the service profit chain: The impact of environmental management practices. Production and operations Management, 12(3):386-403.

Le Meunier-FitzHugh, K. and Piercy, N. F. (2007). Does collaboration between sales and marketing affect business performance? Journal of Personal Selling E Sales Management, 27(3):207-220.

Lee, P., Gillespie, N., Mann, L., and Wearing, A. (2010). Leadership and trust: Their effect on knowledge sharing and team performance. Management learning, 41(4):473-491.

Mollenkopf, D., Gibson, A., and Ozanne, L. (2000). The integration of marketing and logistics functions: an empirical examination of new zealand firms. Journal of business Logistics, 21(2):89.

Nahapiet, J. and Ghoshal, S. (1998). Social capital, intellectual capital, and the organizational advantage. Academy of management review, 23(2):242-266.

Narasimhan, R. and Kim, S. W. (2002). Effect of supply chain integration on the relationship between diversification and performance: evidence from japanese and korean firms. Journal of operations management, 20(3):303-323.

Pagell, M. (2004). Understanding the factors that enable and inhibit the integration of operations, purchasing and logistics. Journal of operations management, 22(5):459-487.

Pelled, L. H. (1996). Demographic diversity, conflict, and work group outcomes: An intervening process theory. Organization science, 7(6):615631.

Petter, S., Straub, D., and Rai, A. (2007). Specifying formative constructs in information systems research. MIS quarterly, pages 623-656.

Prajogo, D. and Olhager, J. (2012). Supply chain integration and performance: The effects of longterm relationships, information technology and sharing, and logistics integration. International Journal of Production Economics, 135(1):514-522.

Richardson, J. G. (1986). Handbook of Theory and Research for the Sociology of Education. Greenwood Publishing Group.
Sarstedt, M., Ringle, C. M., and Hair, J. F. (2017). Partial least squares structural equation modeling. Handbook of market research, 26:1-40.

Srivastava, A., Bartol, K. M., and Locke, E. A. (2006). Empowering leadership in management teams: Effects on knowledge sharing, efficacy, and performance. Academy of management journal, 49(6):1239-1251.

Stank, T. P., Keller, S. B., and Daugherty, P. J. (2001). Supply chain collaboration and logistical service performance. Journal of Business logistics, 22(1):29-48.

Stevens, G. C. (1989). Integrating the supply chain. international Journal of physical distribution $\mathcal{E} M a-$ terials Management.

Swink, M., Narasimhan, R., and Wang, C. (2007). Managing beyond the factory walls: effects of four types of strategic integration on manufacturing plant performance. Journal of operations management, 25(1):148-164.

Tourish, D. and Hargie, C. (1996). Internal communication: key steps in evaluating and improving performance. Corporate Communications: an international journal.

Vargas, G., Cardenas, L., and Matarranz, J. L. (2000). Internal and external integration of assembly manufacturing activities. International Journal of Operations \& Production Management.

Wiengarten, F., Pagell, M., Ahmed, M. U., and Gimenez, C. (2014). Do a country's logistical capabilities moderate the external integration performance relationship? Journal of Operations Management, 32(1-2):51-63.

Wong, K. K.-K. (2013). Partial least squares structural equation modeling (pls-sem) techniques using smartpls. Marketing Bulletin, 24(1):1-32.

Yee, R. W., Yeung, A. C., and Cheng, T. E. (2008). The impact of employee satisfaction on quality and profitability in high-contact service industries. Journal of operations management, 26(5):651668.

Zhao, X., Huo, B., Selen, W., and Yeung, J. H. Y. (2011). The impact of internal integration and relationship commitment on external integration. Journal of operations management, 29(1-2):17-32. 